\title{
Optoelectrical Properties of NilnZnO (NIZO) Thin Films
}

\author{
K. Mensah-Darkwa ${ }^{1}$, A. Dere ${ }^{2}$, Abdullah G. Al-Sehemi ${ }^{3-5}$, Ahmed A. Al-Ghamdi $^{6}$, \\ Ram K. Gupta ${ }^{7, *}$ and F. Yakuphanoglu ${ }^{2,8, *}$
}

${ }^{1}$ Department of Materials Engineering, College of Engineering, Kwame Nkrumah University of Science and Technology, Kumasi, Ghana

${ }^{2}$ Firat University, Nanoscience and Technology Laboratory, Elazig, Turkey

${ }^{3}$ Department of Chemistry, Faculty of Science, King Khalid University, Abha 61413, P.O. Box 9004, Saudi Arabia

${ }^{4}$ Research Center for Advanced Materials Science, King Khalid University, Abha 61413, P.O. Box 9004, Saudi Arabia

${ }^{5}$ Unit of Science and Technology, Faculty of Science, King Khalid University, Abha 61413,P.O. Box 9004, Saudi Arabia

${ }^{6}$ Department of Physics, Faculty of Science, King Abdulaziz University, Jeddah, Saudi Arabia

${ }^{7}$ Department of Chemistry, Pittsburg State University, Pittsburg, KS 66762, USA

${ }^{8}$ Department of Physics, Faculty of Science, Firat University, Elazig, Turkey

\begin{abstract}
This report presents the fabrication and characterization of $x \% \mathrm{Ni}-\operatorname{InZnO}(\mathrm{NIZO})$ Schottky diodes. The structural, optical and electrical properties of the fabricate Al/p-Si / $x \% \mathrm{Ni}-\operatorname{lnZnO} /$ Au photodiodes were investigated. An average visible transmittance of about $75 \%-85 \%$ has been obtained in the visible-light to near-infrared wavelength region. The optical bandgap was $3.17 \pm 0.02 \mathrm{eV}$. Current-Voltage measurements were conducted to analyze the photodiode behavior under dark and light illumination. The reverse bias current increases together with increasing light illumination. The observed I-V results confirm the photoconductive and photovoltaic properties of the fabricated diode. There is an exponential relationship between the current and the voltage in the forward bias, confirming the rectification performance of the photodiode. The electrical properties of the fabricated photodiodes were evaluated using CheungCheung and Norde's methods. The transient photocurrent, capacitance-voltage-frequency and conductance-voltagefrequency plots indicate that the diode is very sensitive to light illumination. We also observe a strong correlation between capacitance and conductance on frequency, this was explained based on the presence of interface states. The obtained results suggest that the Ni-doped InZnO photodiodes can be useful in photovoltaic and optoelectronic applications.
\end{abstract}

Keywords: Ideality factor, bandgap, InZnO, photodiode, Optoelectrical.

\section{INTRODUCTION}

Zinc oxide and its derivatives have been found in several applications such as optics, photonics and data storage [1]. It exhibits a wide bandgap of $3.37 \mathrm{eV}$ and a large free exciton binding energy of $60 \mathrm{meV}$ at normal room temperature, this property allows for efficient excitonic emission at room temperature [2]. Properties such as high transparency in the visible region, lowcost deposition techniques [3], among others has made it an important material in several functional devices such as ultra-violet laser diodes, visible LED's [4, 5], solar cells $[6,7]$, sensors $[8,9]$ and photo-catalyst [10, 11]. $\mathrm{ZnO}$ is used as a transparent electrode in solar application due to its transparency to visible light and

Address correspondence to these authors at the Department of Chemistry, Pittsburg State University, Pittsburg, KS 66762, USA; Tel: 620-235-4763; Fax: 620-235-4002; E-mail: ramguptamsu@gmail.com

Department of Physics, Faculty of Science, Fırat University, Elazig, Turkey; Tel: 0090 5337623815; Fax: 00904242483423; E-mail: fyhan@hotmail.com high conductivity (through doping). Zinc oxide, like other transparent oxides and metal oxide semiconductors, is a promising material for nextgeneration optoelectronic and spintronics applications. It is well-known that the structural, optical and electrical properties depend on morphology, doping elements, doping concentrations, fabrication technologies among others.

Researchers have proposed a selection of elements as dopant to influence the electrical, optical properties and ferromagnetic properties of $\mathrm{ZnO}$. Similar reports by [12-14] have shown that doping with $\mathrm{Al}$ and $\mathrm{Ga}$ or $\mathrm{In}$ can improve the electrical conductivity of $\mathrm{ZnO}$. In another work by [15], solution synthesized Ni-doped: $\mathrm{ZnO}$ exhibited ferromagnetic behavior at $\mathrm{T}_{\mathrm{c}}>350 \mathrm{~K}$, this was attributed to the agglomeration of lattice defects during aggregation. of materials intensively studied for applications to suitable for spintronic applications. In the same work colloidal Ni-doped: $\mathrm{ZnO}$ nanocrystals 


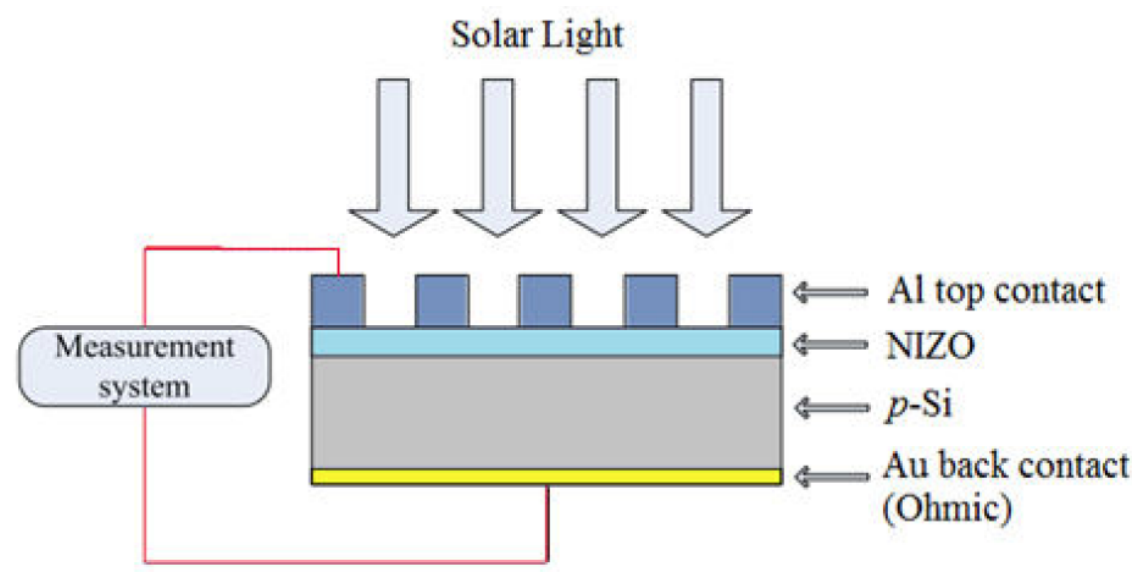

Figure 1: Configuration of NIZO photosensor.

exhibited paramagnetic behavior. Research work by [16], deposited a layer of indium zinc oxide (IZO) on the $n$-type Si substrate for photodetectors applications, using pulsed laser deposition. The samples exhibited substantial photo-induced responses. Also, transmittance exceeded $80 \%$ between NIR to UV light. It must be noted that amorphous indium zinc oxide (IZO) films have attracted tremendous research attention in part due to their wide optical band gap $\left(E_{g}\right.$ $>3.3 \mathrm{eV})$, high carrier mobility $\left(>10 \mathrm{~cm}^{2} \mathrm{~V}^{-1} \mathrm{~s}^{-1}\right)$ and high carrier concentration $\left(>10^{20} \mathrm{~cm}^{-3}\right.$ ) properties, these properties makes it a dependable candidate for optoelectronic applications. For example, Fang et al. [17] have used a pulsed laser deposition technique to fabricate amorphous InZnO films. They reported a high transparency of approximately $80 \%$ in the visible wavelength range. The best device showed opencircuit voltage $(0.24 \mathrm{~V})$, short circuit current density $\left(28.4 \mathrm{~mA} / \mathrm{cm}^{2}\right)$ and fill factor (33.6\%). Low-temperature fabrication of InZnO films has been reported by Hosono [18], these exhibited high transparency and low resistivity. Other researchers have been focusing on investigating IZO for the semiconducting oxide layer for thin-film transistors, solar cells and transparent electrode applications [19-21].

To the best of our knowledge, $x \% \mathrm{Ni}-\ln \mathrm{ZnO}$ system is not well published. Hence, this paper reports on the fabrication and characterization of $\mathrm{Al} / \mathrm{p}-\mathrm{Si} / x \%$ $\mathrm{Ni}-\mathrm{InZnO} / \mathrm{Au}$ thin film photodiode using a spin coating technique. A detailed investigation of the optical properties, structural properties, I-V characteristics, transient photocurrent, capacitance, and conductance dependence on voltage and frequency characteristics have been reported. Our results provide insight into the applicability of $x \% \mathrm{Ni}$ - InZnO systems for optical, electronic and spintronic applications.

\section{EXPERIMENTAL DETAILS}

Samples were prepared using a facial solution method. NIZO solution with a molarity of $0.5 \mathrm{M}$ was prepared using nickel nitrate, indium nitrate, and zinc acetate as precursors. These three precursors were dissolved in 2-methoxy ethanol and monoethanolamine as solvent and stabilizer, respectively. Acetic acid was added to the mixture to create a homogenous solution of $\mathrm{In}: \mathrm{Zn}$ (fixed at a molar ratio of $3: 2)$. Ni content was varied from 10 to $40 \%$ in the interval of $10 \%$. The mixture was stirred for $1 \mathrm{~h}$ at $70{ }^{\circ} \mathrm{C}$. The $x \% \mathrm{Ni}-\operatorname{InZnO}$ solution (NIZO) was spin-coated on $p$-type silicon having $\mathrm{Au}$ ohmic contact (contact area $=$ $3.14 \times 10^{-2} \mathrm{~cm}^{2}$ ). The samples were dried in a vacuum oven at $200{ }^{\circ} \mathrm{C}$ for $20 \mathrm{~min}$ to obtain solid films. The schematic diagram of the fabricated photosensor is shown in Figure 1. The absorption properties of the samples were investigated using a diffuse reflectance UV-vis spectrometer. Electrical characteristics such as $I-V, C-t, C-V, G-V$ of the diodes were performed using a computer-controlled FYTRONIX FY5000 electronic device characterization system.

\section{RESULTS AND DISCUSSION}

\subsection{Optical Properties of NilnZnO (NIZO) Thin Films}

The optical properties and bandgap of the fabricated devices were evaluated. The reflectance, transmittance, and absorbance of the devices were studied in the wavelength range of $200-1200 \mathrm{~nm}$. The absorbance, transmittance and reflectance plots are shown in Figure $\mathbf{2 a}, \mathbf{b}$ and $\mathbf{c}$, respectively. The average transmittances exceed $75 \%$ to $80 \%$ in the visible-light to the NIR wavelength region for all NIZO films, indicating that $\mathrm{Ni}$ content has negligible effects on the film transmittance. There is a larger absorption in the 

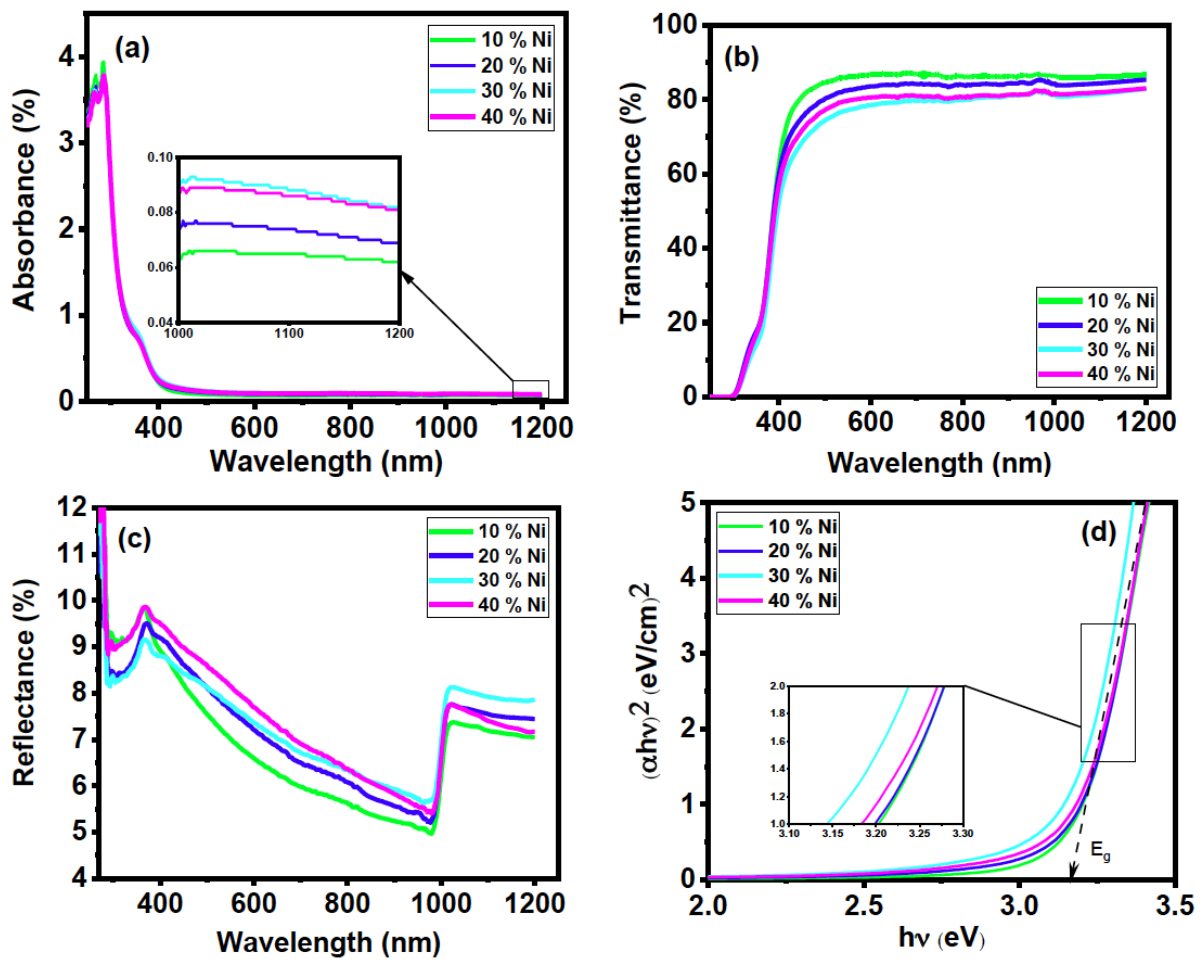

Figure 2: Optical absorbance spectra (a) Optical transmittance spectra (b) Optical reflectance spectra (c) Tauc's plots (d) of 10 $\%, 20 \%, 30 \%$, and $40 \%$ Ni dopant in InZnO.

UV region, for all devices studied; the absorption edge is around $380 \mathrm{~nm}$. Also, we observe for all samples high transparency in the visible regime (Figure $\mathbf{2 b}$ ). The value of reflectance decreases in the visible-light region, however, there is a sharp increase at about 980 $\mathrm{nm}$ and it saturates in the IR region (Figure 2c).

The absorption coefficient $(\alpha)$ and the incident photon energy $(h v)$ of the absorbance spectra are related by equation (1), the optical band gap was determined from the following equation [22]:

$\alpha h v=\left[C\left(h v-E_{g}\right)\right]^{\frac{1}{2}}$

Where $C$ is a constant, $h$ is the Planck's constant and $v$ the frequency of the incident photon and $E_{g}$ is the optical bandgap. The optical bandgap of the films was extracted from Tauc's plot (Figure 2d) as explained in [23, 24], an extrapolated straight-line from the high energy region of the $(\alpha h v)^{2}$ vs. $h v$ plots intercepts the energy axis, the intercept is used to estimate the bandgap. Figure 2d illustrates Tauc's plot estimation of the optical bandgap values of $10 \%, 20$ $\%, 30 \%$, and $40 \% \mathrm{Ni}$ (NIZO). The optical band gap $E_{g}$ was extracted from the intercept as $3.17 \pm 0.02 \mathrm{eV}$. This value agrees well with the literature reported by [25].

\subsection{Current-Voltage Characteristics of NilnZnO (NIZO) Thin Film}

The structural properties of the samples were studied using atomic force microscopy. The AFM analysis of the NIZO samples is shown in Figure 3. NIZO samples with 10, 20 and $30 \% \mathrm{Ni}$ doping showed a thick film with cracks at low magnification, whereas at high magnification we observe a homogenous film. On the contrary, the sample with $40 \% \mathrm{Ni}$ doping exhibited the formation of nanoparticles. The particle distribution of the NIZO particles was almost homogenous. To further understand the usefulness of this behavior to photodiode applications, $I-V$ experiments were conducted to estimate the electrical parameters of the fabricated photodiodes. $I-V$ experiments at room temperature were performed under dark and solar light illumination intensities. Figure $\mathbf{4 a - d}$ depicts the curves of the $\mathrm{Al} / \mathrm{p}$-Si/NilnZnO/Au photosensor for $10,20,30$ and $40 \% \mathrm{Ni}$ content, respectively. All the fabricated sensors exhibited typical rectification behavior, confirmed by the non-linear $I-V$ characteristics plots. As seen in Figure 4, the reverse bias current at a particular applied voltage under increasing solar light illumination is greater than the dark current, while in the forward bias, the current remains constant with increasing solar light illumination. The observed light sensitivity behavior was explained based on photoexcitation of 


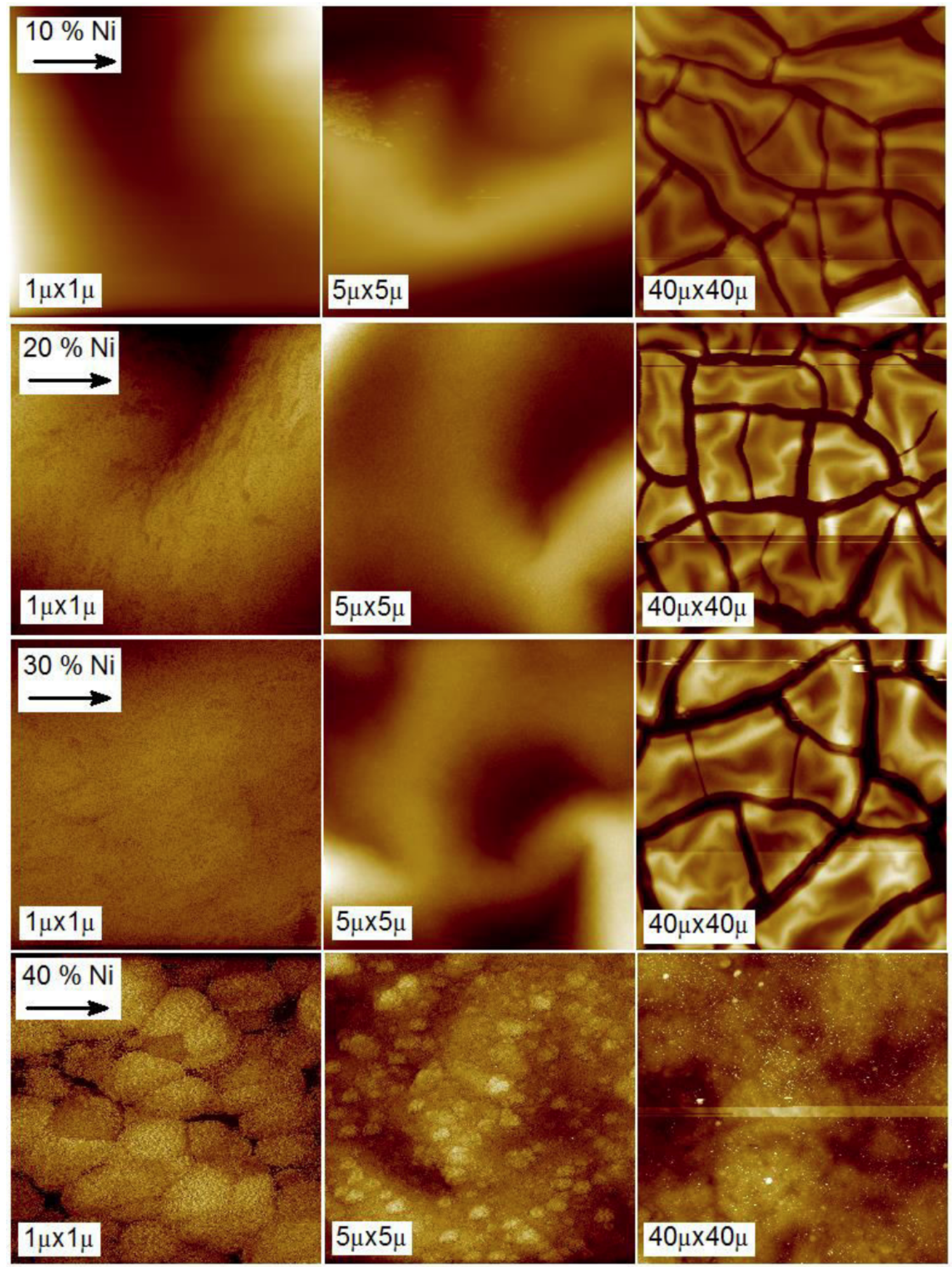

Figure 3: AFM images of $x \% \mathrm{Ni}-\operatorname{lnZnO}(\mathrm{NIZO})$ films at the magnifications shown. 

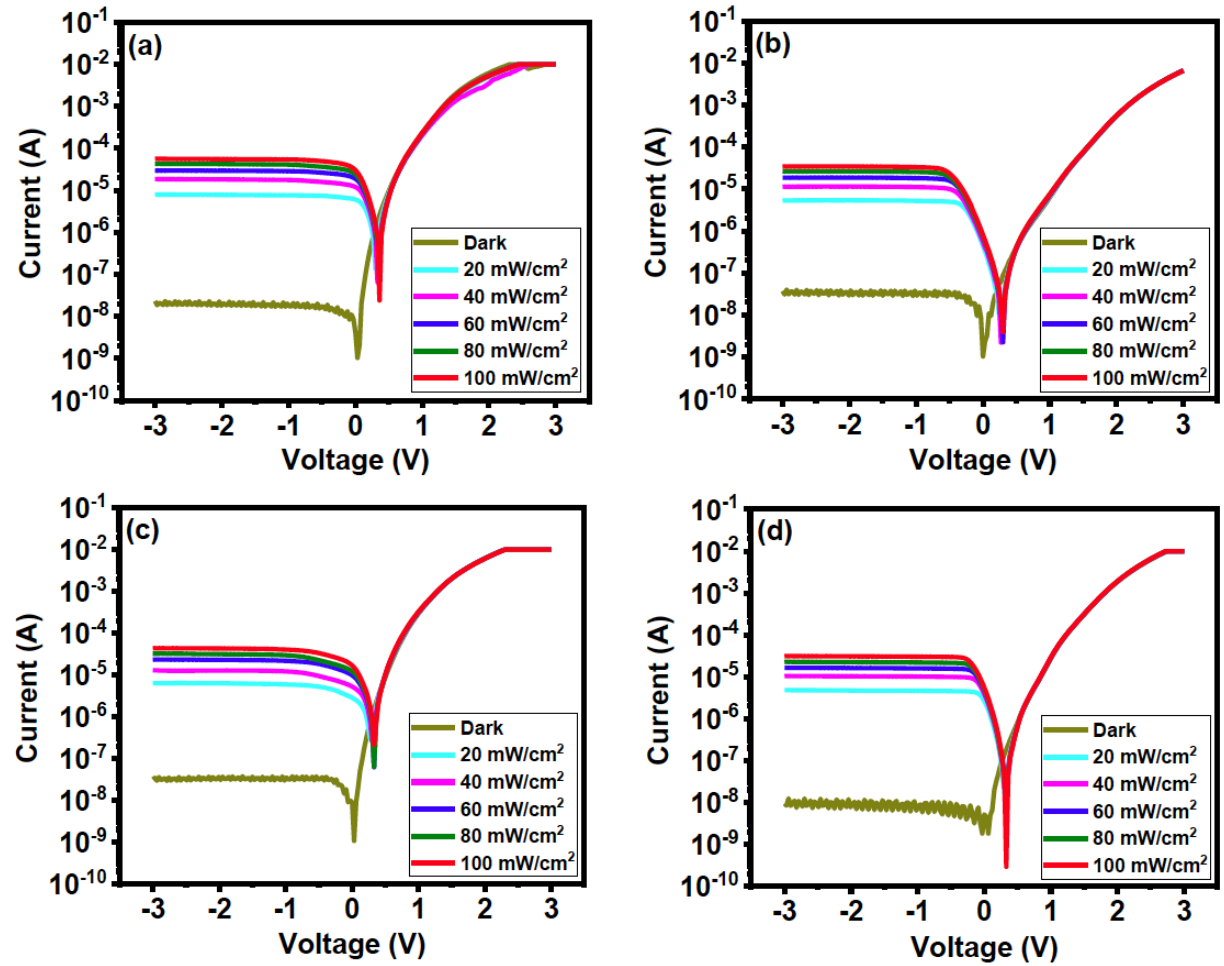

Figure 4: $I-V$ characteristics under dark and various illumination for (a) $10 \%$ (b) $20 \%$ (c) $30 \%$ and (d) $40 \% \mathrm{Ni}$ dopant in InZnO.

Table 1: Photovoltaic Parameters of the Diodes

\begin{tabular}{|c|c|c|c|c|}
\hline Sample & RR @ $\pm \mathbf{3 V}$ & $\mathbf{I}_{\text {photo }} I_{\text {dark }}(-\mathbf{3} \mathbf{V})$ & $\mathbf{V}_{\text {oc }}(\mathbf{V})$ & $\mathbf{I}_{\text {sc }}(\mathbf{A})$ \\
\hline \hline $10 \% \mathrm{Ni}$ & $4.25 \times 10^{5}$ & $2.50 \times 10^{2}$ & 0.360 & $2.43 \times 10^{-8}$ \\
\hline $20 \% \mathrm{Ni}$ & $1.83 \times 10^{5}$ & $9.27 \times 10^{2}$ & 0.299 & $3.99 \times 10^{-9}$ \\
\hline $30 \% \mathrm{Ni}$ & $3.50 \times 10^{5}$ & $1.53 \times 10^{3}$ & 0.331 & $2.12 \times 10^{-7}$ \\
\hline $40 \% \mathrm{Ni}$ & $1.08 \times 10^{6}$ & $3.51 \times 10^{3}$ & 0.330 & $2.93 \times 10^{-10}$ \\
\hline
\end{tabular}

charge carriers been transported from the valence band to the defect-perturbed host state [26, 27]. Similar, the observed linearity at high forward-bias voltages is attributed to series resistance and interface states [28-30], these will be discussed in subsequent sections. The rectification ratio $(R R)$ given by $I_{F} / I_{R}\left(I_{F}, I_{R}\right.$ for forward, reverse current) was estimated from the $I-V$ plots at $\pm 3 \vee$ (Table 1). The diode photosensitivity was calculated as $I_{\text {photo }} / I_{\text {dark }}$ at $-3 \mathrm{~V}$ (Table 1). Under 100 $\mathrm{mW} / \mathrm{cm}^{2}$ of solar light illumination, Table 1 shows the values for the open-circuit voltage $\left(\mathrm{V}_{\mathrm{oc}}\right)$ and short circuit current $\left(\mathrm{I}_{\mathrm{sc}}\right)$. As seen, the rectification ratio of the fabricated photodiodes was of the order $10^{5}$, however, the $40 \% \mathrm{Ni}$ samples had one order higher value compared to the other samples. The high photosensitivity values support the rectification behavior of the samples.
For the fabricated photodiode, it is expected that the dominant transport mechanism is controlled by the thermionic emission of the majority carriers. CheungCheung [31] and Norde's methods [32] were used to fit the experimental data to thermionic emission models to estimate the electrical parameters for the samples as follows. The $I-V$ characteristics of the fabricated device are controlled by [33]:

$$
I=I_{s}\left[\exp \left(\frac{q V_{D}}{n k T}\right)-1\right]
$$

The ideality $(n)$, temperature $(\mathrm{T})$, Boltzmann constant $(k)$, applied voltage across the diode $\left(V_{D}\right)$, and the electronic charge $(q)$, is related to the reverse saturation current $\left(I_{s}\right)$ by $[34,35]$; 


$$
I_{s}=A \times A^{* *} \times T^{2} \exp \left(\frac{-q \Phi_{B}}{k T}\right)
$$

Where $A$ is the active device area, $A^{* *}$ is the Richardson constant (32 A/cm ${ }^{2} \mathrm{~K}^{2}$ for $p$-Si) and $\Phi_{B}$ represents the Schottky barrier height.

For $V_{D}>3 k T / q, V_{D}=V-(I R)$ and $J=I / /_{A}[31,36$, 37], the equation 2 and 3 can be written as:

$$
I=A A^{* *} T^{2} \exp \left(-\chi^{0.5} \delta\right) \exp \left(\frac{\Phi_{B}}{k T}\right)\left[\exp \left(\frac{q\left(V-I R_{s}\right)}{n K T}\right)-1\right]
$$

And it follows that:

$V=R_{s} A J+n \Phi_{B}+\frac{n}{\beta} \ln \left(\frac{J}{A^{* *} T^{2} \exp \left(-\chi^{0.5} \delta\right)}\right)$

Where $\chi, \delta$ which represent the mean tunneling barrier height and interfacial oxide thickness due to the inherent oxide layer, respectively [38]. Cheung's method was used to obtain the ideality factor $(n)$, the barrier height $\left(\Phi_{B}\right)$ and series resistance $\left(R_{S}\right)$. The photodiode $I-V$ relation with the series resistance is given by [31]:

$\frac{d V}{d(\ln J)}=\frac{n k T}{q}+R_{s} A J$

Figure 5 depicts the experimental $d V / d \ln J$ vs. $J$ plots. The experimental electrical parameters $\Phi_{B}, n$, and $R_{s}$ were determined from the intercepts and slopes. Thus, from Figure 5 (a-d) the values of $n$ and $R_{s}(d V / d l n J)$ were obtained from the intercepts and slopes of the $d V / d \ln J$ vs. $J$ plots for each fabricated photodiode. Using the $n$ value calculated from Eq. (6), a plot of $H(J)$ vs. $J$ (Figure $5 \mathbf{e}-\mathbf{h}$ ) also yields a straight line. As shown in Eq. (7);

$$
H(J)=V-n \frac{k T}{q} \ln \left(\frac{I}{A \times A^{* *} T^{2}}\right)=n \Phi_{B}+R_{s} A J
$$

The slope is further used to recalculate $R_{s}(H(J))$, which was used to check the consistency of this approach, whereas the intercept is used to determine $\Phi_{B}$. Norde's method has been used by several researchers to calculate and compare the barrier height $\left(\Phi_{B}\right)$ and series resistance $\left(R_{s}\right)$ of diodes [32, 39]. In using this method, the Norde function $F(V, I)(E q .8)$ is plotted against voltage ( $V$ ) (Figure 5e-h)

$$
F(V, I)=\frac{V}{\gamma}-\frac{k T}{q} \ln \left(\frac{1}{A \times A^{* *} T^{2}}\right)
$$

The barrier height $\left(\Phi_{B}\right)$ is calculated as follows:

$$
\Phi_{B}=F\left(V_{0}\right)+\frac{V_{0}}{\gamma}-\frac{k T}{q}
$$

Where $\mathrm{y}$ is a dimensionless integer greater than $n$ (from Cheung - Cheung Method), and $F\left(V_{0}\right), V_{0}$ corresponds to the minimum value of plots (shown on Figure 5e-h) [32, 40]. Table 2 summarizes the electrical parameters extracted using the two methods.

The variation of the photocurrent with illumination intensity was studied using the following relation to analyze the photoconductive mechanism of the diodes;

$$
I_{p h}=\alpha P^{m}
$$

where $I_{p h}$ is photocurrent, $\mathrm{P}$ is the illumination intensity, $m$ is an exponent and $\alpha$ is a constant. Figure 6, shows the graph of $\log \left(I_{p h}\right)$ verses $\log (P)$ for the various photodiodes. An exponential value $0.5 \leq m \leq 1$ suggests that the photoconductive mechanism of the photodiode is controlled by the existence of continuous distribution of trap levels [41], while values above 1 can be attributed to mononuclear recombination photoconduction mechanism. The values of the exponent $(m)$ was calculated from the gradient of $\log \left(I_{p h}\right)$ vs. $\log (P)$. The observed $m$ values were $1.21,1.14,1.23$ and 1.10 for $10 \%, 20 \%$, $30 \%$, and $40 \% \mathrm{Ni}$ (NIZO), respectively. Since the value of $m$ is higher than 1 in all the prepared samples, the photoconduction mechanism can be considered as mononuclear recombination photoconduction.

\subsection{Transient Photocurrent, Capacitance-Voltage and Conductance-Voltage Characteristics of $x \%$ Ni-InZnO (NIZO) Thin Film}

The transient photocurrent-time measurement was used to further analyze the photoconduction mechanism of the fabricated photodiodes. Figure 7 shows a typical ON/OFF light switching the behavior of our device as a function illumination intensity. The device was exposed to the light radiation for $10 \mathrm{~s}$ under a fixed bias voltage and corresponding current flow in the circuit was measured.

As seen in Figure $\mathbf{7 a - d}$, the $\mathrm{ON}$ cycle produces an instant increase in the photocurrent, while the OFF cycle restores the current back to its initial value. This 

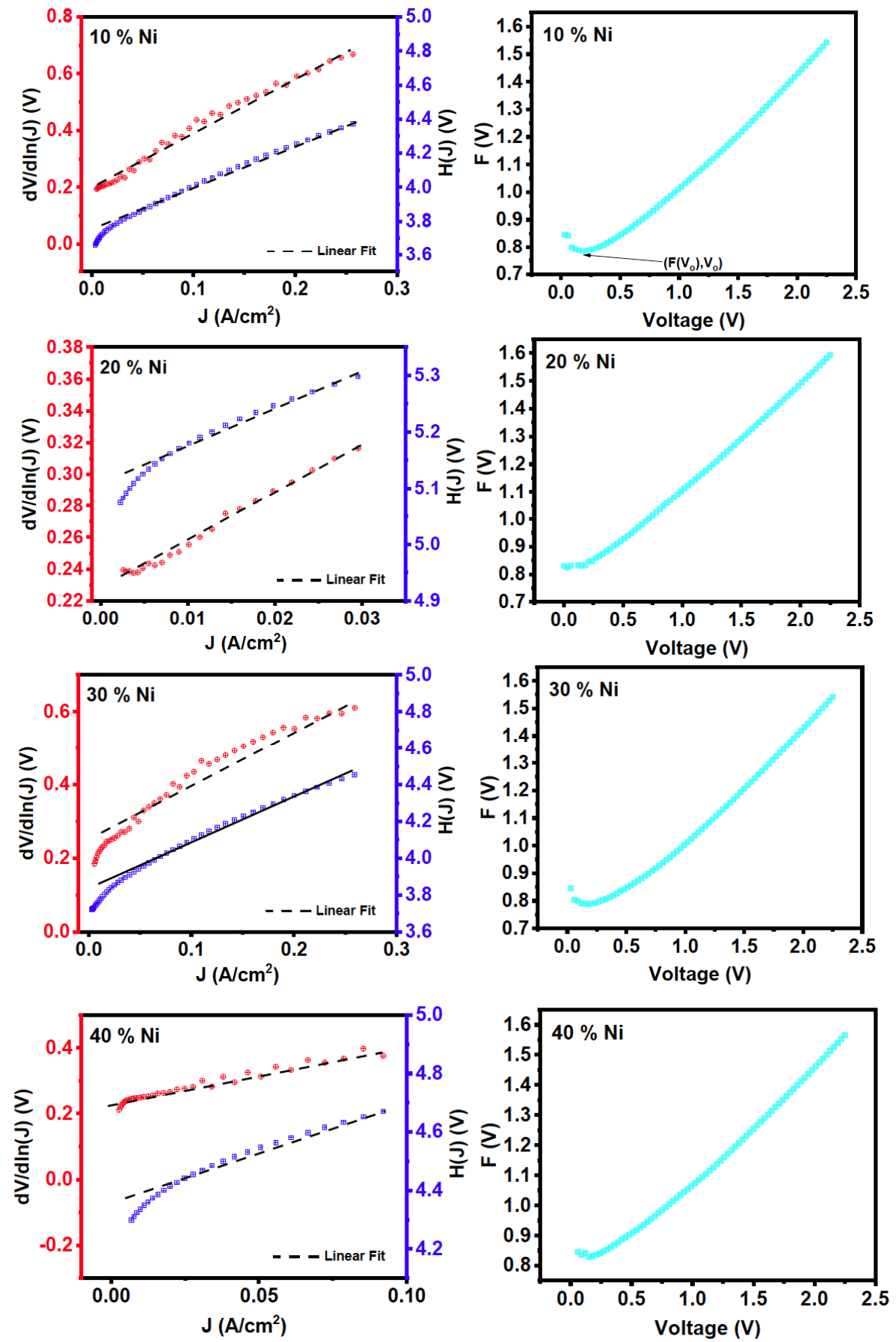

Figure 5: Plots of $d V / d I n J$ (left) and $H(J)$ (right) as a function of current density $J$ calculated from forward bias $I-V$ characteristics (NIZO).

Table 2: Electrical Diode Parameters

\begin{tabular}{|c|c|c|c|c|c|c|}
\hline \multirow{3}{*}{ Samples } & \multicolumn{4}{|c|}{ Cheung - Cheung Method } & \multirow{2}{*}{\multicolumn{2}{|c|}{ Nord's Method }} \\
\hline & \multicolumn{2}{|c|}{$d V / d \ln J$} & \multicolumn{2}{|c|}{$H(J)$} & & \\
\hline & $n$ & $R_{s}(\Omega)$ & $\Phi_{B}(\mathrm{eV})$ & $R_{s}(\Omega)$ & $\Phi_{B}(\mathrm{eV})$ & $R_{s}(\Omega)$ \\
\hline $10 \% \mathrm{Ni}$ & 5.27 & 84.85 & 0.70 & 94.32 & 0.85 & 1206.47 \\
\hline $20 \% \mathrm{Ni}$ & 5.39 & 106.05 & 0.76 & 108.27 & 0.86 & 3271.96 \\
\hline $30 \% \mathrm{Ni}$ & 5.46 & 101.73 & 0.79 & 104.60 & 0.82 & 2058.20 \\
\hline
\end{tabular}




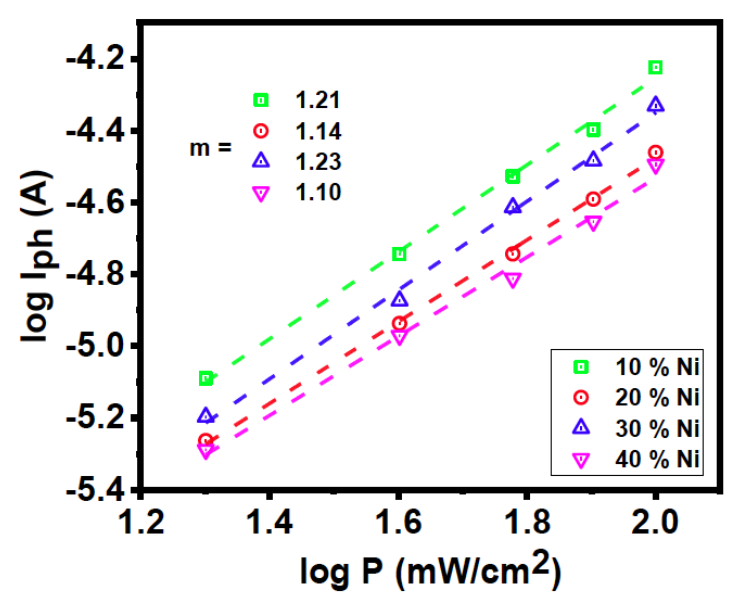

Figure 6: Plot of $\log \left(I_{P H}\right)$ vs. $\log (P)$ for the photodiodes (at bias voltage of $-3 \mathrm{~V}$ ).

observed cyclic behavior is synonymous with the increase in free charge carriers contributing to photogenerated electrons. On the OFF cycle, charge carriers are trapped in deep levels, hence the observed decrease in the photocurrent [37, 42-44].

The junction properties of the fabricated diodes were investigated using capacitance and conductance dependence on voltage and frequency. Figures $\mathbf{8}$ and $\mathbf{9}$ depict the plots of $C-V-f$ and $G-V-f$, respectively. As seen in Figure 8, the capacitance remains constant with frequency at the positive voltage regime, while in
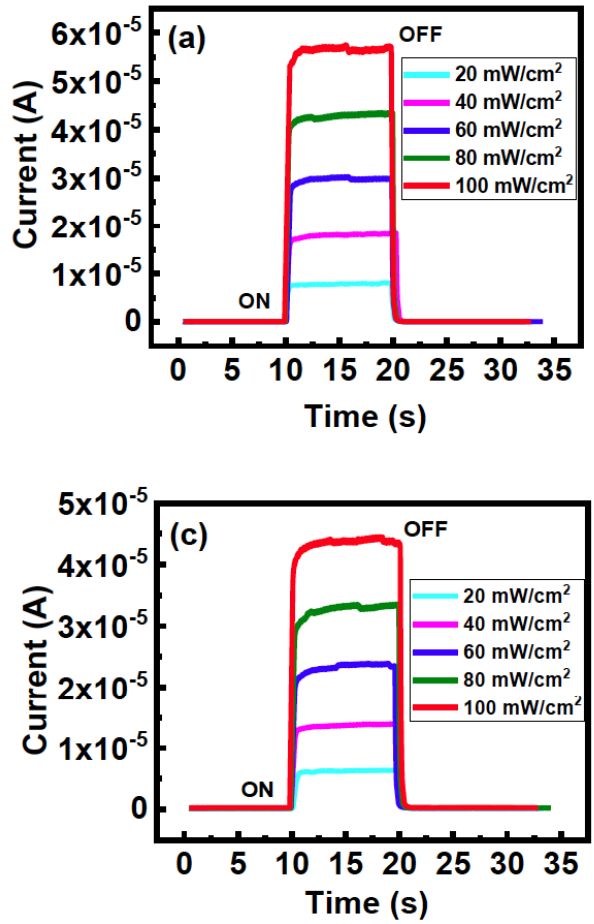

the negative regime it decreases with increasing frequency. The $C-V-f$ plots show a peak in the negative voltage regime (Figure 8). The observed peaks decrease in magnitude with increasing frequency, the presence of interface states is responsible for this phenomenon [45-47]. We observe that the interface charges have negligible effects on the capacitive behavior of the photodiode at higher frequencies. Similarly, from Figure 9, the conductance remains constant with frequency at the positive voltage regime, however, in the negative regime, it increases while frequency increases. This observed behavior of conductance can also be attributed to the presence of the interface states series resistance [48]. The series resistance $\left(R_{s}\right)$ of the fabricated photodiodes was investigated using the Nicollian and Goetzberger method [30], where;

$$
R_{s}=\frac{G_{m}}{G_{m}^{2}+\left(\omega C_{m}\right)^{2}}
$$

where $C_{m}$ is the measured capacitance and $G_{m}$ is the measured conductance. Figure 10 shows the variations of $R_{S}$ with applied bias voltage at various frequencies. The series resistance decreases with increasing frequency. This observed behavior can be explained on the basis of localized interface states and frequencydependent charges such as fixed oxide charge,
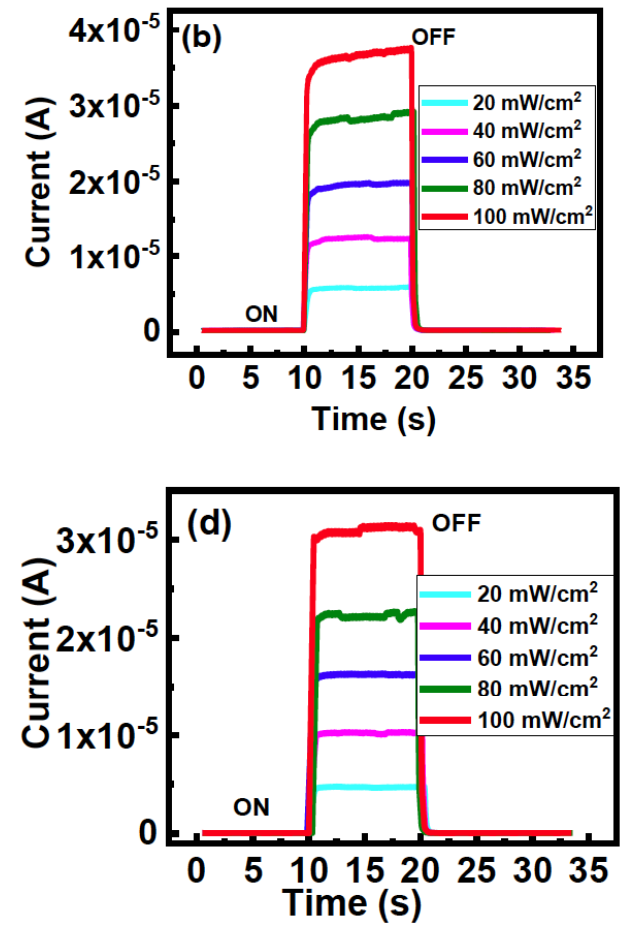

Figure 7: Transient photocurrent measurements of the photodiodes as a function of illumination (a) $10 \%$ (b) $20 \%$ (c) $30 \%$ and (d) $40 \%$ Ni dopant in InZnO. 

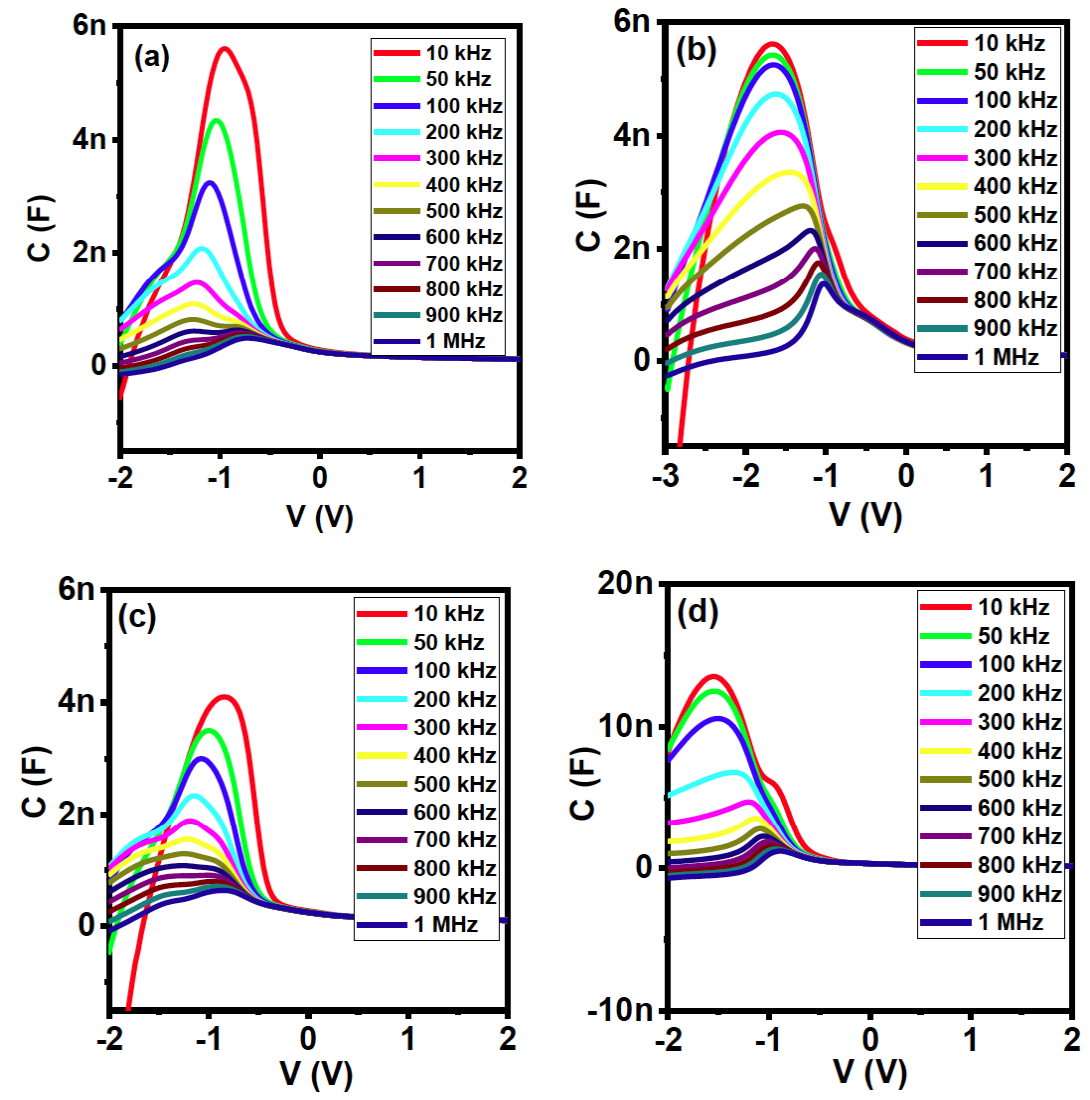

Figure 8: C-V plots of the photodiode at various frequencies (a) $10 \%$ (b) $20 \%$ (c) $30 \%$ and (d) $40 \%$ Ni dopant in $\operatorname{lnZnO}$.
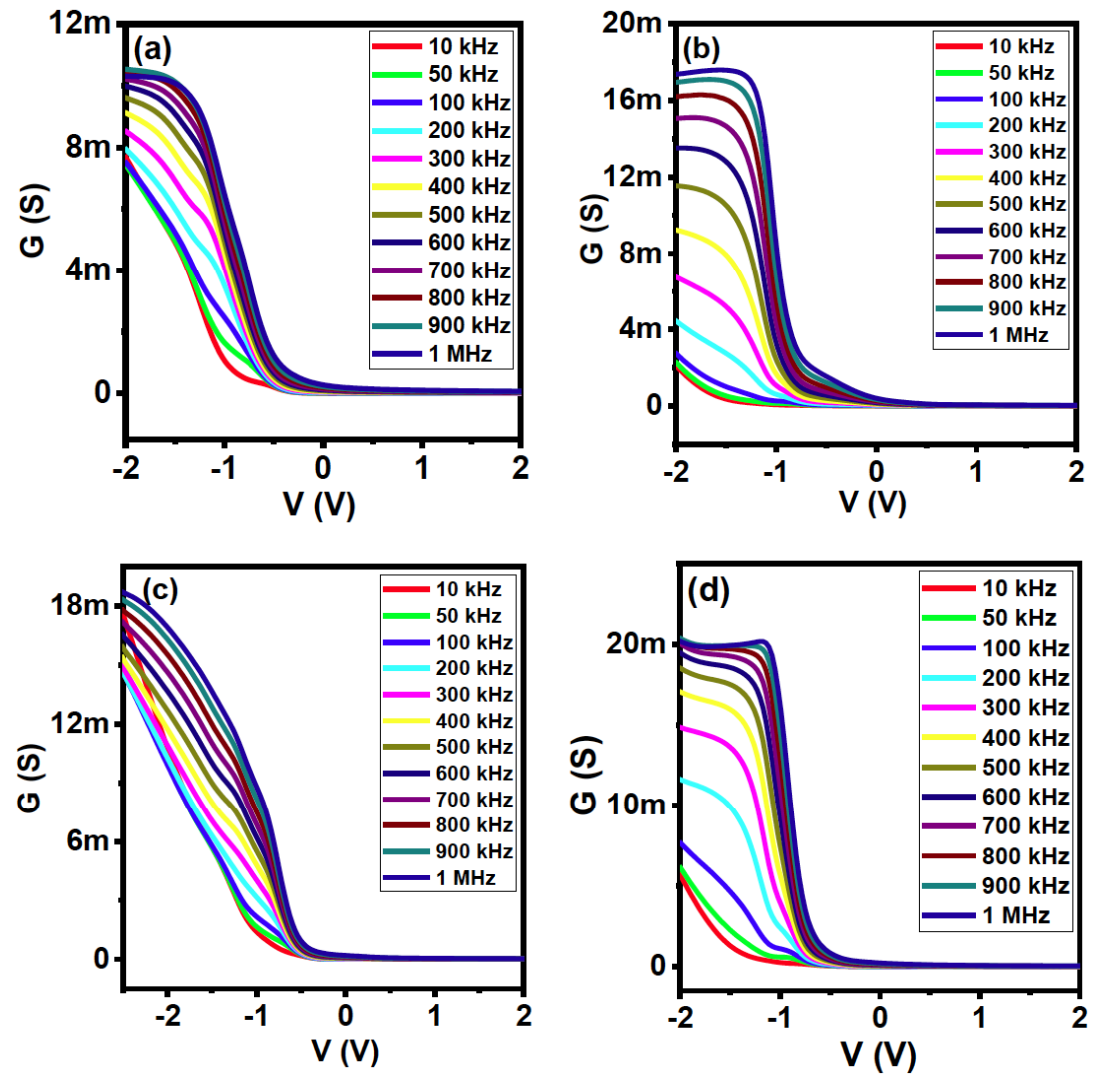

Figure 9: G-V plots of the photodiode at various frequencies (a) $10 \%$ (b) $20 \%$ (c) $30 \%$ and (d) $40 \%$ Ni dopant in InZnO. 

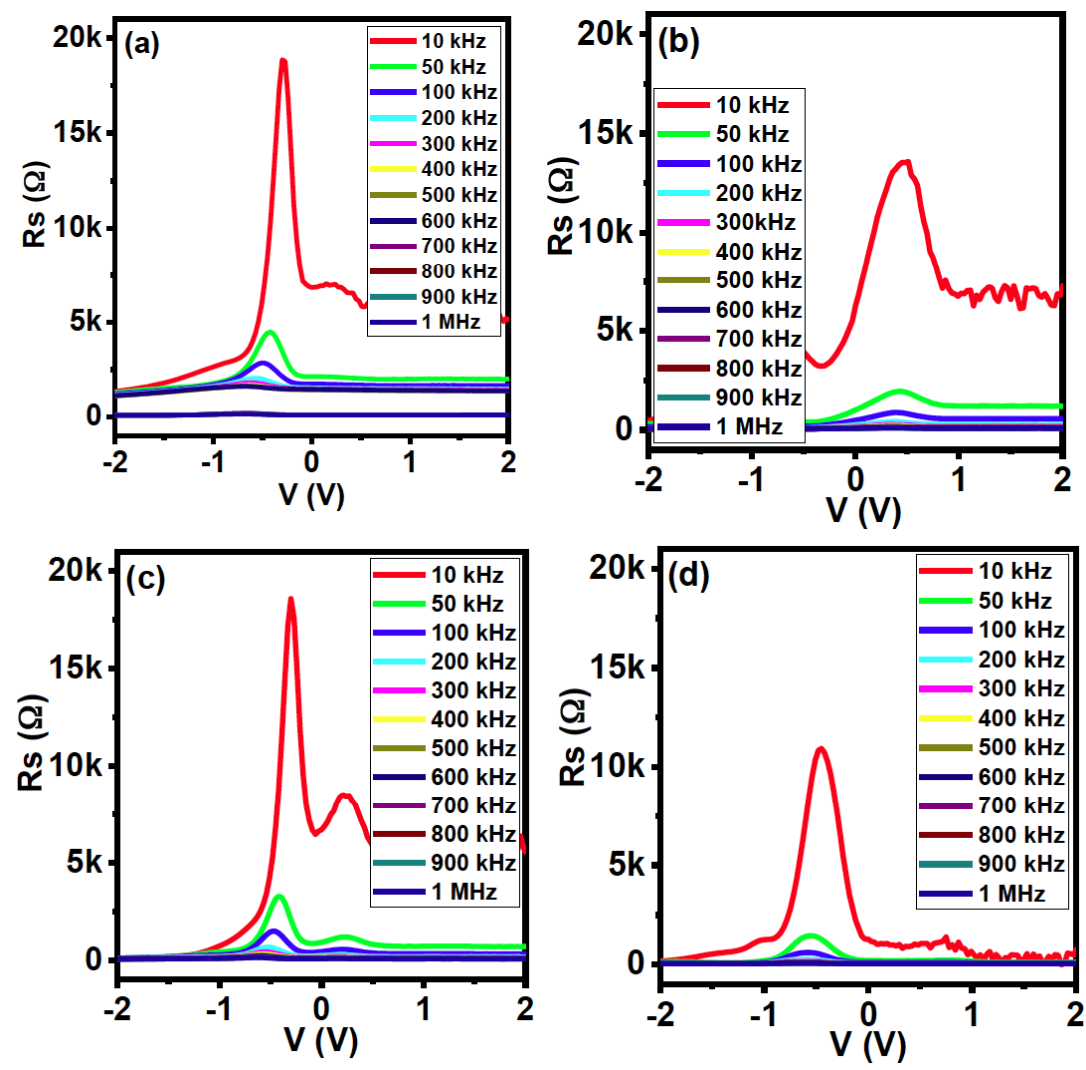

Figure 10: $R_{S}-V$ plots of the photodiode at various frequencies

(a) $10 \%$ (b) $20 \%$ (c) $30 \%$ and (d) $40 \%$ Ni dopant in InZnO.

interface charge, mobile oxide charge and oxidetrapped charge [49]. Also, the observed peak intensity decreases with increasing frequency. This observed behavior was attributed to changes in interface states, where at high frequencies, the charges in the interface states cannot follow the AC signal.

In order to analyze the effects of series resistance and the true-space charge capacitance and conductance, $C-V-f$ and $G-V-f$ plots was corrected using $R_{s}$ as follows [50, 51]:

$$
\begin{gathered}
C_{a d j}=\frac{\left[G_{m}^{2}+\left(\omega C_{m}\right)^{2}\right] C_{m}}{a^{2}+\left(\omega C_{m}\right)^{2}} \\
G_{a d j}=\frac{\left[G_{m}^{2}+\left(\omega C_{m}\right)^{2}\right] a}{a^{2}+\left(\omega C_{m}\right)^{2}}
\end{gathered}
$$

And

$a=G_{m}-\left[G_{m}^{2}+(\omega C m)^{2}\right] R_{s}$

The effects of frequency on the $C_{a d j}-V$ (compensated capacitance) and $G_{a d j}-V$ (compensated conductance) plots are depicted in Figures 11 and 12, respectively. The presence of the interface states is responsible for the behavior of the $C_{a d j}-V$, and $G_{a d j}-V$ graphs. To further analyze this behavior, the density of the interface states was studied. The density of interface states $\left(D_{i t}\right)$ can be determined from the capacitance and conductance voltage experiments using the method proposed by Hill-Coleman [52], where

$$
D_{i t}=\frac{2}{q A} \frac{\left(G_{m} / \omega\right)_{\max }}{\left[\left(\left(G_{m} / \omega\right)_{\max } C_{o x}\right)^{2}+\left(1-C_{m} / C_{o x}\right)^{2}\right]}
$$

where $\left(G_{m} / \omega\right)_{\max }$ is the maximum measured conductance and $C_{o x}$ is the capacitance of the interfacial layer. The $D_{i t}$ values of the diode were estimated from Eq. 15 and the graphs of $D_{i t}$ with frequency are depicted in Figure 13. Clearly, from Figure 13, we observe a relation between the density of interface states and frequency where the $D_{i t}$ value decreases with increasing frequency. This behavior of $D_{i t}$ is due to a decrease in numbers of interface charge carries following the frequency of the applied electric field. 

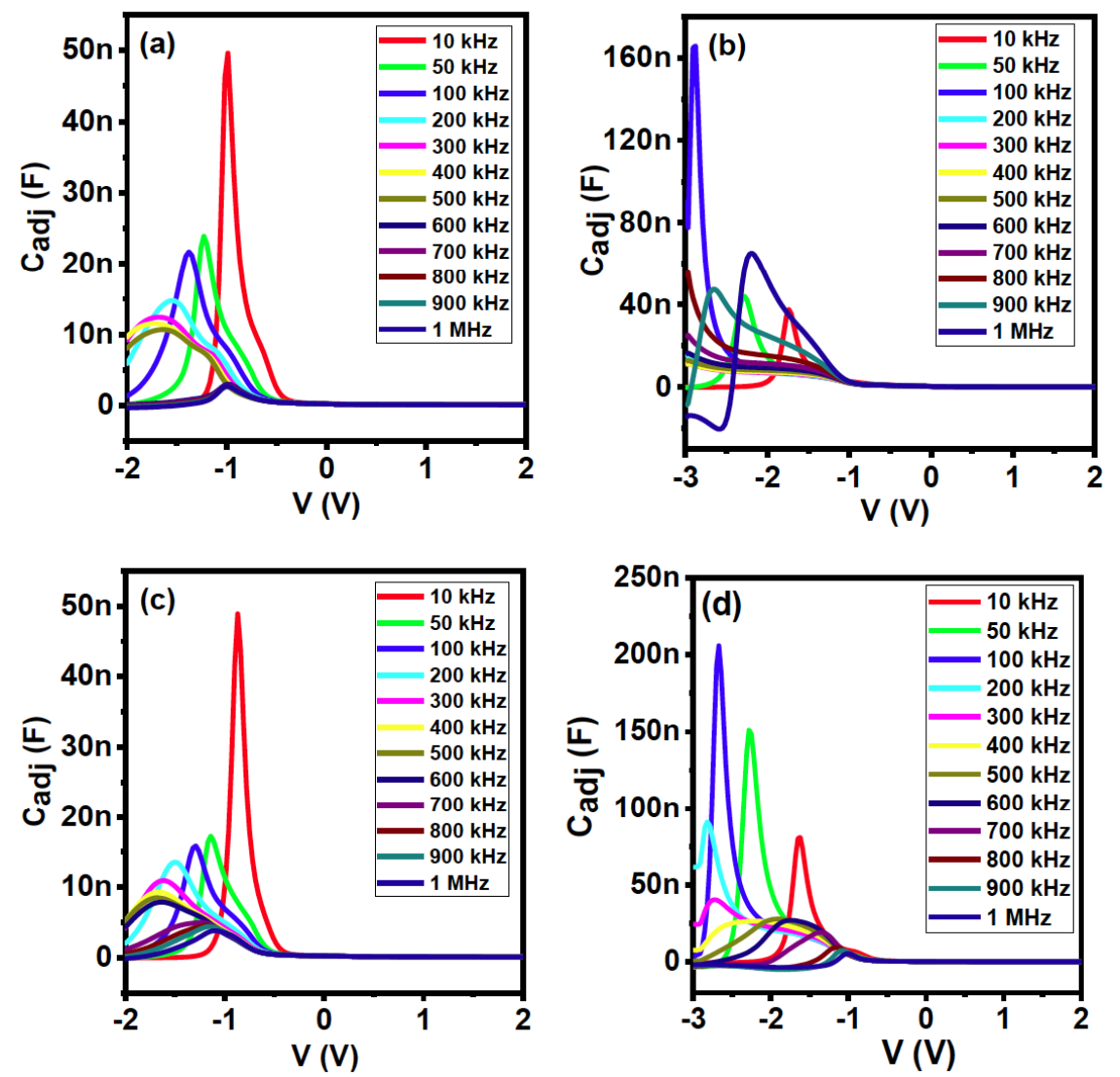

Figure 11: $C_{a d j}-V$ plots of the photodiode at various frequencies (a) $10 \%$ (b) $20 \%$ (c) $30 \%$ and (d) $40 \%$ Ni dopant in InZnO.
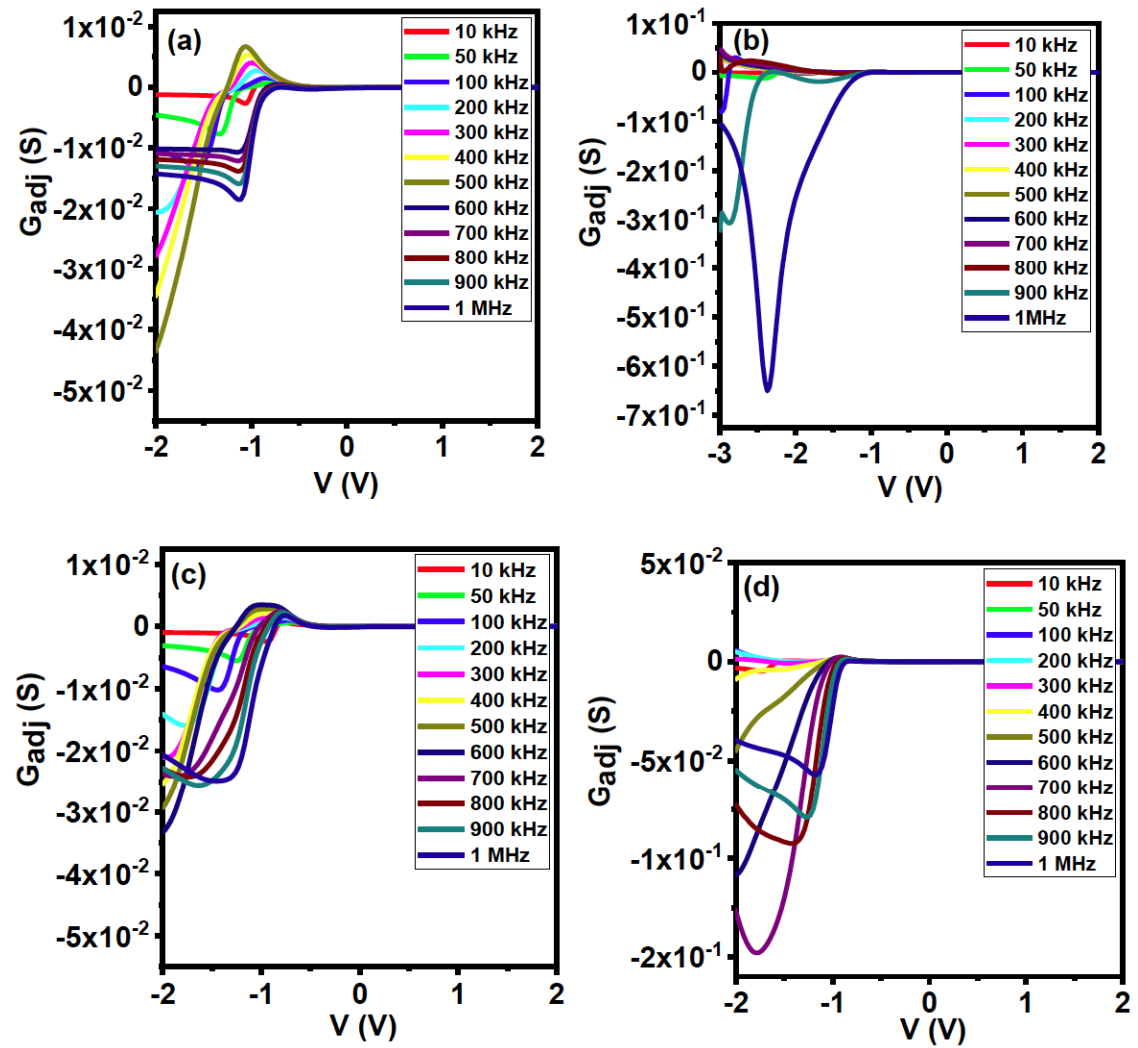

Figure 12: $G_{a d j}-V$ plots of the photodiode at various frequencies (a) $10 \%$ (b) $20 \%$ (c) $30 \%$ and (d) $40 \%$ Ni dopant in InZnO. 

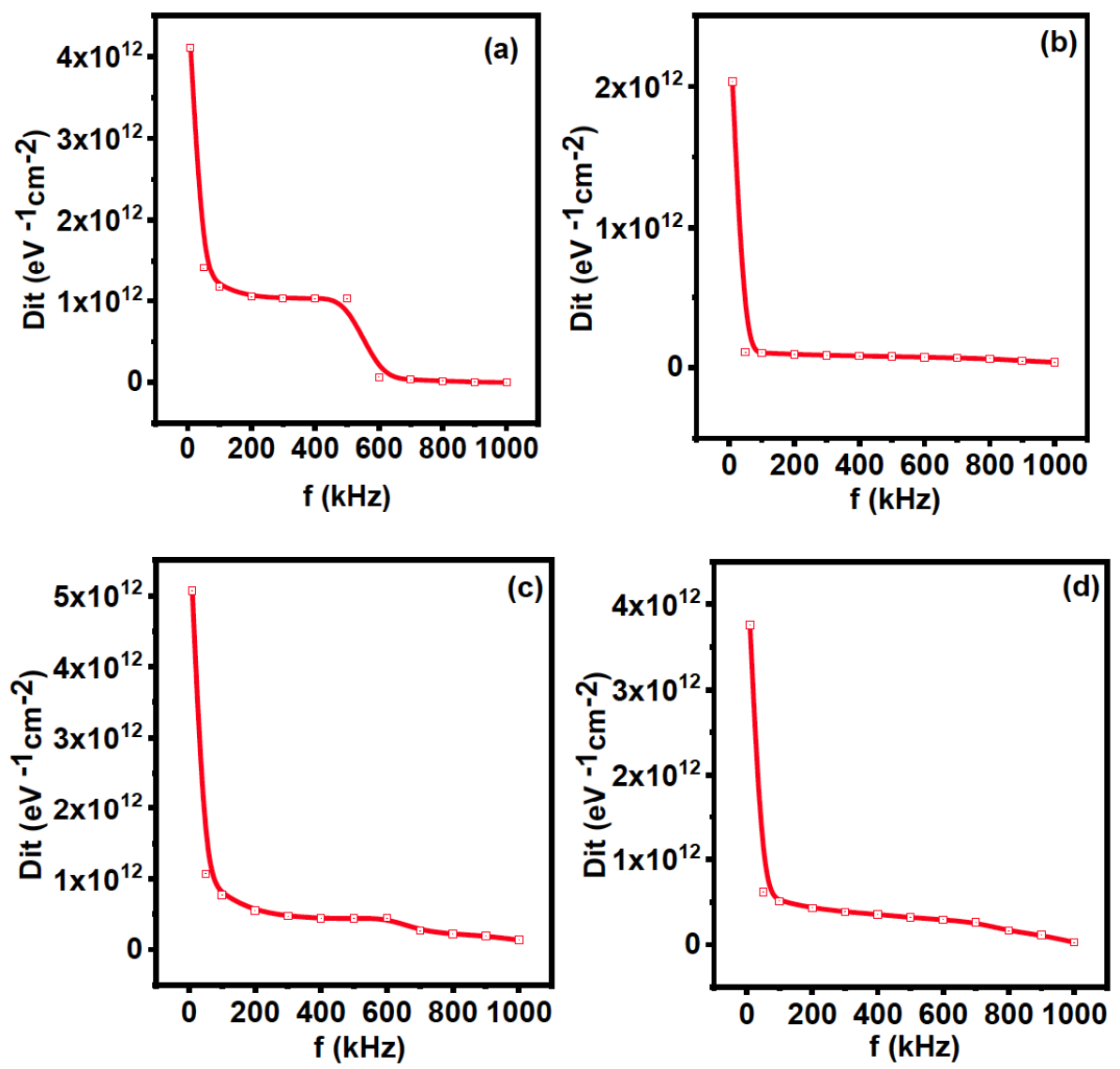

Figure 13: Dit plots of the photodiode at various frequencies (a) $10 \%$ (b) $20 \%$ (c) $30 \%$ and (d) $40 \% \mathrm{Ni}$ dopant in InZnO.

\section{CONCLUSION}

In summary, we have successfully prepared $\mathrm{Al} / \mathrm{p}-\mathrm{Si}$ I $x \% \mathrm{Ni}-\ln \mathrm{ZnO} / \mathrm{Au}$ photodiodes using a spin coating method. The effect of the $\mathrm{Ni}$ concentration on the structural, optical and electrical characteristics of thin films was investigated. Optical transmittance measurements show> $80 \%$ in the wavelength from 400 to $1000 \mathrm{~nm}$. Using Tauc's plot, the obtained optical band gap value ranged between $3.17 \pm 0.02 \mathrm{eV}$. The observed behavior shows excellent rectifying properties. The electrical parameters of the photodiodes as a function of doping and dark/light illumination were estimated using modified CheungCheung and Norde's method.

The transient photocurrent as a function of time increased to a fixed value on exposure to light and decreased to its original value when the light was turned off. The frequency-dependent capacitance and conductance were explained on the bases of the presence of interface states. From the aforementioned results, we can conclude that the NIZO fabricated diode can be used in optoelectronic applications.

\section{ACKNOWLEDGEMENTS}

Authors would like to acknowledge the support of the King Khalid University for this research through a grant RCAMS/KKU/002-16 under the (Research Center for Advanced Materials Science) at King Khalid University, Kingdom of Saudi Arabia; and the Government of Ghana book and research allowance.

\section{REFERENCES}

[1] W.M. Kwok, A.B. Djurišić, Y.H. Leung, D. Li, K.H. Tam, D.L. Phillips, W.K. Chan, Applied Physics Letters, 89 (2006) 183112.

https://doi.org/10.1063/1.2378560

[2] W. Zhong Lin, Journal of Physics: Condensed Matter, 16 (2004) R829. https://doi.org/10.1088/0953-8984/16/25/R01

[3] S. Mridha, D. Basak, Journal of Applied Physics, 101 (2007) 083102. https://doi.org/10.1063/1.2724808

[4] M. Ding, D. Zhao, B. Yao, B. Li, Z. Zhang, D. Shen, Applied Physics Letters, 98 (2011) 062102 https://doi.org/10.1063/1.3549304

[5] S.N. Das, J.-H. Choi, J.P. Kar, T.I. Lee, J.-M. Myoung, Materials Chemistry and Physics, 121 (2010) 472-476. https://doi.org/10.1016/j.matchemphys.2010.02.007

[6] A.R. Rao, V. Dutta, Nanotechnology, 19 (2008) 445712 https://doi.org/10.1088/0957-4484/19/44/445712 
[7] G. Hu, W. Guo, R. Yu, X. Yang, R. Zhou, C. Pan, Z.L. Wang, Nano Energy, 23 (2016) 27-33.

https://doi.org/10.1016/j.nanoen.2016.02.057

[8] R. Araneo, A. Rinaldi, A. Notargiacomo, M. Pea, S. Celozzi, Sensors and Actuators A: Physical, 244 (2016) 166-173. https://doi.org/10.1016/j.sna.2016.04.031

[9] B. Wu, Z. Lin, M. Sheng, S. Hou, J. Xu, Applied Surface Science, 360, Part B (2016) 652-657.

https://doi.org/10.1016/j.apsusc.2015.11.037

[10] H.-J. Wang, L.-N. Wang, Y. Cao, Journal of Environmental Chemical Engineering, 3 (2015) 2263-2272. https://doi.org/10.1016/j.jece.2015.08.018

[11] R. Lamba, A. Umar, S.K. Mehta, S.K. Kansal, Journal of Alloys and Compounds, 653 (2015) 327-333. https://doi.org/10.1016/j.jallcom.2015.08.220

[12] D. Greiner, N. Papathanasiou, A. Pflug, F. Ruske, R. Klenk, Thin Solid Films, 517 (2009) 2291-2294. https://doi.org/10.1016/j.tsf.2008.10.107

[13] L. Wong, S. Chiam, J. Huang, S. Wang, J. Pan, W. Chim, Applied Physics Letters, 98 (2011) 022106. https://doi.org/10.1063/1.3541885

[14] B. Kotlyarchuk, V. Savchuk, M. Oszwaldowski, Crystal Research and Technology, 40 (2005) 1118-1123. https://doi.org/10.1002/crat.200410502

[15] P.V. Radovanovic, D.R. Gamelin, Physical review letters, 91 (2003) 157202 https://doi.org/10.1103/PhysRevLett.91.157202

[16] H.-W. Fang, T.-E. Hsieh, J.-Y. Juang, Applied Surface Science, 345 (2015) 295-300. https://doi.org/10.1016/j.apsusc.2015.03.169

[17] H.-W. Fang, S.-J. Liu, T.-E. Hsieh, J.-Y. Juang, J.-H. Hsieh, Solar Energy, 85 (2011) 2589-2594. https://doi.org/10.1016/j.solener.2011.07.016

[18] H. Hosono, Journal of Non-Crystalline Solids, 352 (2006) 851-858.

https://doi.org/10.1016/j.jnoncrysol.2006.01.073

[19] Y.B. Xiao, S.M. Kong, E.H. Kim, C.W. Chung, Solar Energy Materials and Solar Cells, 95 (2011) 264-269. https://doi.org/10.1016/j.solmat.2010.02.016

[20] Y. Li, L. Lan, P. Xiao, Z. Lin, S. Sun, W. Song, E. Song, P. Gao, D. Wang, H. Ning, J. Peng, RSC Advances, 5 (2015) 51440-51445.

https://doi.org/10.1039/C5RA09435F

[21] C.G. Choi, S.-J. Seo, B.-S. Bae, Electrochemical and SolidState Letters, 11 (2008) H7-H9.

https://doi.org/10.1149/1.2800562

[22] R. Chauhan, A. Kumar, R.P. Chaudhary, Research on chemical Intermediates, 38 (2012) 1483-1493.

https://doi.org/10.1007/s11164-011-0478-5

[23] J. Tauc, R. Grigorovici, A. Vancu, physica status solidi (b), 15 (1966) 627-637.

https://doi.org/10.1002/pssb.19660150224

[24] P. Sharma, K. Sreenivas, K.V. Rao, Journal of Applied Physics, 93 (2003) 3963-3970.

https://doi.org/10.1063/1.1558994

[25] H.-W. Fang, T.-E. Hsieh, J.-Y. Juang, Solar Energy Materials and Solar Cells, 121 (2014) 176-181.

https://doi.org/10.1016/j.solmat.2013.11.003

[26] H. Aydin, A. Tataroğlu, A.A. Al-Ghamdi, F. Yakuphanoglu, F. El-Tantawy, W.A. Farooq, Journal of Alloys and Compounds, 625 (2015) 18-25.

https://doi.org/10.1016/j.jallcom.2014.11.035

[27] C. Aksu Canbay, A. Dere, K. Mensah-Darkwa, A. Al-Ghamdi, Z. Karagoz Genç, R.K. Gupta, F. Yakuphanoglu, Applied Physics A, 122 (2016) 1-11. https://doi.org/10.1007/s00339-016-0208-3
[28] S.M. Sze, D.J. Coleman, A. Loya, Solid-State Electron., 14 (1971) 1209-1218

https://doi.org/10.1016/0038-1101(71)90109-2

[29] R.T. Tung, Materials Science and Engineering: R: Reports, 35 (2001) 1-138

https://doi.org/10.1016/S0927-796X(01)00037-7

[30] E.H. Nicollian, A. Goetzberger, A.D. Lopez, Solid-State Electronics, 12 (1969) 937-944. https://doi.org/10.1016/0038-1101(69)90014-8

[31] S.K. Cheung, N.W. Cheung, Applied Physics Letters, 49 (1986) 85-87. https://doi.org/10.1063/1.97359

[32] H. Norde, Journal of Applied Physics, 50 (1979) 5052-5053. https://doi.org/10.1063/1.325607

[33] M. Zhu, J. Zhang, Z. Wang, L. Wan, X. Chen, Physica E: Low-dimensional Systems and Nanostructures, 43 (2010) 515-520. https://doi.org/10.1016/j.physe.2010.09.009

[34] R.K. Gupta, R.A. Singh, Materials Chemistry and Physics, 86 (2004) 279-283. https://doi.org/10.1016/j.matchemphys.2004.03.003

[35] S.M. Sze, K.K. Ng, Physics of Semiconductor Devices, Wiley, 2006. https://doi.org/10.1002/0470068329

[36] Y. An, A. Behnam, E. Pop, G. Bosman, A. Ural, Journal of Applied Physics, 118 (2015) 114307. https://doi.org/10.1063/1.4931142

[37] F. Yakuphanoglu, K. Mensah-Darkwa, A.A. Al-Ghamdi, R.K Gupta, W.A. Farooq, Microelectronic Engineering, 160 (2016) 27-33 https://doi.org/10.1016/j.mee.2016.03.001

[38] H.C. Card, E.H. Rhoderick, Journal of Physics D: Applied Physics, 4 (1971) 1589. https://doi.org/10.1088/0022-3727/4/10/319

[39] M.S.P. Reddy, V.R. Reddy, C.-J. Choi, Journal of Alloys and Compounds, 503 (2010) 186-191. https://doi.org/10.1016/j.jallcom.2010.04.230

[40] R.K. Gupta, F. Yakuphanoglu, K. Ghosh, P.K. Kahol, Microelectronic Engineering, 88 (2011) 3067-3069. https://doi.org/10.1016/j.mee.2011.05.023

[41] N.M. Khusayfan, Journal of Alloys and Compounds, 666 (2016) 501-506. https://doi.org/10.1016/j.jallcom.2016.01.102

[42] J. áAnthony Byrne, B. Eggins, P.M. Dunlop, Analyst, 123 (1998) 2007-2012. https://doi.org/10.1039/a803885f

[43] X. Huang, X. Zhang, H. Jiang, Journal of power sources, 248 (2014) 434-438. https://doi.org/10.1016/j.jpowsour.2013.09.094

[44] A. Tataroğlu, H. Tuncer, A.A. Al-Ghamdi, A. Dere, B. Arif, S. Yol, N. Ozdemir, F. El-Tantawy, F. Yakuphanoglu, Synthetic Metals, 206 (2015) 15-23.

https://doi.org/10.1016/j.synthmet.2015.04.007

[45] M. Nath, A. Roy, Physica B: Condensed Matter, 482 (2016) 43-50.

https://doi.org/10.1016/j.physb.2015.12.007

[46] S. Demirezen, A. Kaya, Ö. Vural, Ş . Altındal, Materials Science in Semiconductor Processing, 33 (2015) 140-148. https://doi.org/10.1016/j.mssp.2015.01.050

[47] S. Karataş, F. Yakuphanoglu, F.M. Amanullah, Journal of Physics and Chemistry of Solids, 73 (2012) 46-51. https://doi.org/10.1016/.jpcs.2011.09.020

[48] A. Tataroğlu, O. Dayan, N. Özdemir, Z. Serbetci, A.A. AlGhamdi, A. Dere, F. El-Tantawy, F. Yakuphanoglu, Dyes and Pigments, 132 (2016) 64-71. https://doi.org/10.1016/i.dyepig.2016.04.044 
[49] E.H. Nicollian, J.R. Brews, MOS (metal oxide semiconductor) physics and technology, Wiley, 1982.

[50] O.A. Al-Hartomy, R.K. Gupta, A.A. Al-Ghamdi, F. Yakuphanoglu, Synthetic Metals, 195 (2014) 217-221. https://doi.org/10.1016/j.synthmet.2014.06.001
[51] R. Ertuğrul, A. Tataroğlu, Radiation Effects and Defects in Solids, 169 (2014) 791-799.

https://doi.org/10.1080/10420150.2014.950265

[52] W.A. Hill, C.C. Coleman, Solid-State Electronics, 23 (1980) 987-993.

https://doi.org/10.1016/0038-1101(80)90064-7

Received on 14-12-2019

DOI: http://dx.doi.org/10.31875/2410-2199.2019.06.10

(C) 2019 Mensah-Darkwa et al.; Zeal Press

This is an open access article licensed under the terms of the Creative Commons Attribution Non-Commercial License (http://creativecommons.org/licenses/by-nc/3.0/) which permits unrestricted, non-commercial use, distribution and reproduction in any medium, provided the work is properly cited. 